\title{
Chitinolytic enzymes from bacterium inhabiting human gastrointestinal tract - critical parameters of protein isolation from anaerobic culture
}

\author{
Jarmila Dušková1凶, Galina Tishchenko', Evgenia Ponomareva², Jiří Šimůnek³, Ingrid Kop- \\ pováa ${ }^{3}$, Tereza Skálová ${ }^{1}$, Andrea Štěpánkovả ${ }^{1}$, Jindřich Hašek ${ }^{3}$ and Jan Dohnálek ${ }^{1}$
}

IInstitute of Macromolecular Chemistry, Academy of Sciences of the Czech Republic, Praha, Czech Republic, ${ }^{2}$ nnstitute of Macromolecular Compounds, Russian Academy of Sciences, St. Petersburg, Russia; ${ }^{3}$ Institute of Animal Physiology and Genetics, Academy of Sciences of the Czech Republic, Praha, Czech Republic

The object of this study are chitinolytic enzymes produced by bacterium Clostridium paraputrificum J4 isolated from the gastrointestinal tract of a healthy human. In particular, we focus on the development of purification protocols, determination of properties of the enzymes and their activity profiles. The process of bacteria cultivation and isolation of chitinolytic complex of enzymes showing specific activities of endo-, exo-chitinase and $\mathrm{N}$-acetyl- $\beta$-glucosaminidase was optimized. A range of various purification procedures were used such as ultrafiltration, precipitation, chromatographic separations (ion-exchange, size exclusion, chromatofocusing) in altered combinations. The optimal purification protocol comprises two or three steps. Individual samples were analyzed by SDS/PAGE electrophoresis and after renaturation their activity could be detected using zymograms. Mass spectroscopy peptide fragment analysis and MALDI analysis of the purest samples indicate presence of endochitinase B (molecular mass about $85 \mathrm{kDa}$ ) and of 60 kDa endo- and exochitinases.

Keywords: chitinolytic enzymes, anaerobic cultivation, protein isolation

Received: 05 March, 2011; revised: 12 May, 2011; accepted: 08 June, 2011; available on-line: 13 June, 2011

\section{INTRODUCTION}

In many chitinolytic systems chitin is hydrolyzed by chitin depolymerases which have wide-ranging applications, particularly in biotechnology (Dahiya et al., 2006). Chitinolytic enzymes have been found in mammals, plants, fungi, and many bacterial species originating particularly from soil, wastes and digestive tract of insectivorous birds and mammals. They are also produced by chitinolytic bacteria, which have been found in human faeces (Šimůnek et al., 2002; Vernazza et al., 2005). It is generally accepted that commensal intestinal microflora has a major impact on gastrointestinal function and thereby on human health. The presence of bacterial chitinases in human colon can play an important role as part of defence mechanisms against fungal invasion (Vicencio et al., 2008).

Chitinolytic enzymes have been intensively studied by enzymologists and molecular biologists in the last decades (Fukamizo, 2000). Generally, several methods have been used for their production (Dahiya et al., 2006) in- cluding two basic techniques, namely production by the natural source or by a genetically modified organism, which are usually followed by a two-step purification process (Chang et al., 2010).

The whole spectrum of chitinolytic enzymes produced by the human intestinal microflora has not yet been described at the molecular level and little information is available about their specific properties and synergies of their action. In our study we focus on isolation of individual chitinolytic enzymes produced by bacterium Clostridium paraputrificum J4. The proteins were isolated from crude bacterial supernatant containing a complex of endo- and exo-chitinases and $N$-acetyl- $\beta$ glucosaminidase.

Production of a rich extracellular extract and its harvesting have been optimized and currently two major directions of purification of the enzymes are optimized. A reliable protocol for preparation of pure and homogenous enzyme samples is essential for further identification, characterization and sequencing of the protein products. Here we present optimized separation protocols as well as partial characterization of the isolated enzymes. Once characterized in detail the individual enzymes can be produced recombinantly in the future to facilitate easier purification and preparation of samples suitable for structure analysis by single crystal x-ray diffraction.

\section{MATERIALS AND METHODS}

Clostridium paraputrificum strain J4 was cultivated anaerobically as described previously (Tishchenko et al., 2010). Cells were removed by centrifugation and the supernatant was used for enzyme isolation.

The concentrated supernatant was subjected to several alternative purification procedures. The first step was either ultrafiltration or column chromatography. Precipitation and desalting were also tested as alternative first steps. Here we describe two alternative and successful purification protocols.

The first purification protocol consisted of the following steps: 1) Clarification of the culture fluids by cen-

e-mail: duskova@imc.cas.cz 
trifugation; 2) Concentration of the bacteria-free supernatant by subsequent filtration through $100-\mathrm{kDa}$ and $30-$ $\mathrm{kDa}$ ultrafiltration membranes (Millipore); 3) Removal of low molecular mass solutes from retentate R30 (solutes passed through the $100-\mathrm{kDa}$ membrane but retained by the $30-\mathrm{kDa}$ membrane) by column chromatography on a modified anion exchanger Dowex- $1 \times 2$ (Dow Chemical Company) using $100 \mathrm{mM}$ Tris/ $\mathrm{HCl}$ buffer, $\mathrm{pH}$ 7.5, and a linear elution gradient of $\mathrm{NaCl}$ in the buffer $(0-1$ $\mathrm{M})$; 4) Repeated chromatography of the eluate fractions on anion exchangers: DEAE-Sepharose Fast Flow (GE Healthcare Bio-Sciences AB) and $\mathrm{CIM}^{\circledR} \mathrm{Q}$ membranelike HPLC supports (BIA Separations) and 5) Separation of the pre-purified chitinolytic enzymes by gel permeation chromatography on Superose 12 (Tricorn 10/300, GE Healthcare Bio-Sciences AB) in $0.05 \mathrm{M} \mathrm{Na}_{2} \mathrm{HPO}_{4} /$ $\mathrm{KH}_{2} \mathrm{PO}_{4}$ buffer containing $0.1 \mathrm{M} \mathrm{NaCl}, \mathrm{pH}$ 7.0.

The second, alternative, purification scheme consisted of the following steps: 1) Filtration of the concentrated supernatant through a $0.22 \mu \mathrm{m}$ polyvinylidene fluoride membrane (PVDF, Millipore); 2) Concentration approximately 10 times using a $10-\mathrm{kDa}$ polyethersulfone membrane of a Microsep centrifugal device (Pall Life Sciences) and equilibration in $0.1 \mathrm{M}$ phosphate buffer, $\mathrm{pH}$ 7.0; 3) Size exclusion chromatography using a Tricorn 10/300 column and Superdex 200 (GE Healthcare Life Sciences), $0.1 \mathrm{M} \mathrm{Na} \mathrm{HPO}_{4} / \mathrm{NaH}_{2} \mathrm{PO}_{4}$ buffer, pH 7.0, $0.05 \mathrm{M} \mathrm{NaCl}$; 4) Ion exchange chromatography - linear elution method - using MiniQ 4.6/50 PE column (polystyrene/divinyl benzene matrix; GE Healthcare Life Sciences), loading buffer $0.05 \mathrm{M}$ Tris/ $\mathrm{HCl}, \mathrm{pH} 8$, elution buffer $0.05 \mathrm{M}$ Tris/ $\mathrm{HCl}, 1.0 \mathrm{M} \mathrm{NaCl}, \mathrm{pH} 8$.

Zymograms were prepared according to a published method for detection of endoglucanases (Flint et al., 1994). Proteins were separated by SDS/PAGE. Renaturation of enzymes after separation was done by washing $(15 \mathrm{~min})$ of the gel in $1 \%(\mathrm{v} / \mathrm{v})$ Triton X 100 and repeated washing ( 3 times, $15 \mathrm{~min}$ ) in $25 \mathrm{mM}$ phosphate buffer, $\mathrm{pH} \mathrm{6}$, to remove SDS. Exochitinase, endochitinase and $N$-acetyl- $\beta$-glucosaminidase zymographies were per-

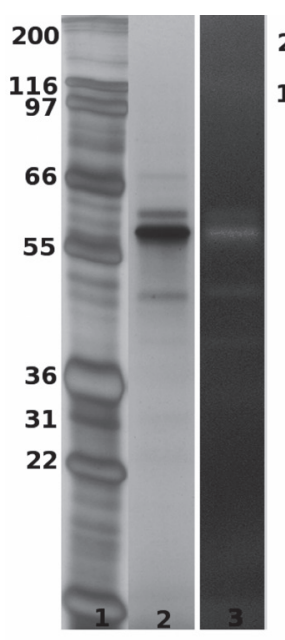

a

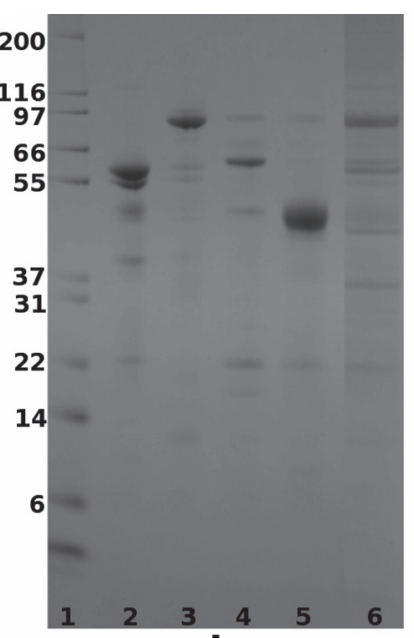

b
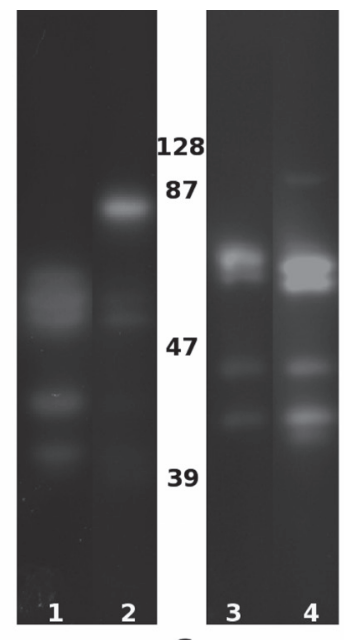

C formed using overlays containing 4-methylumbelliferyl$\beta$-D-N,N'-diacetylchitobioside, 4-methylumbelliferyl- $\beta-\mathrm{D}-$ $N, N^{\prime}, N^{\prime \prime}$-triacetylchitotrioside or 4 methylumbelliferyl- $N$ acetyl- $\beta$-D-glucosaminide (Sigma), respectively (300 $\mu \mathrm{g}$. $\mathrm{ml}^{-1}$ in $1 \%$ agarose gel, $45^{\circ} \mathrm{C}$ ) (Khan et al., 2003). Overlayed gels were incubated at $39^{\circ} \mathrm{C}$ until bands were evident when viewed under ultraviolet light. This technique allowed visualization of multiple isoenzymes. For estimation of sample molar mass the Kaleidoscope prestained protein standards were used (BIO-RAD).

Purified enzymes in $0.05 \mathrm{M}$ Tris $/ \mathrm{HCl}, \mathrm{pH}$, at a concentration of $0.2-2 \mathrm{mg} \cdot \mathrm{ml}^{-1}$ were subjected to Matrix Assisted Laser Desorption \& Ionization Time-ofFlight mass spectroscopy analysis with a BIFLEX III spectrometer (Bruker). Acquired molecular masses were matched against calculated values for known chitinolytic enzymes of Clostridium paraputrificum M-21.

\section{RESULTS AND DISCUSSION}

The bacterium grown on colloidal chitin produced a complete array of chitinolytic enzymes. Significant activities of endochitinase, exochitinase and chitosanase were excreted extracellulary (specific activity 301.2, 281.6 and $268.3 \mathrm{nkat} \cdot \mu \mathrm{g}^{-1}$, respectively). The activities of endochitinase and $N$-acetyl- $\beta$-glucosaminidase were increasing from 20 to $50^{\circ} \mathrm{C}$ with a temperature optimum of $50^{\circ} \mathrm{C}$. Endochitinase as well as $N$-acetyl- $\beta$-glucosaminidase were active in the whole range of $\mathrm{pH}$ 4-8. Optima for $N$-acetyl- $\beta$-glucosaminidase and endochitinase were found at $\mathrm{pH} 6.5$ and 6.0, respectively.

The first purification protocol yields partially separated enzymes of molecular masses in the range of $40-60 \mathrm{kDa}$ (Fig. 1a). Two enzymes with molecular mass of about $60 \mathrm{kDa}$ are present in the original culture fluids (Fig. 1b, lane 6). Their molecular masses were determined by MALDI analysis as $61.2 \mathrm{kDa}$ and $62.7 \mathrm{kDa}$. The former one is preferentially isolated in the first purification protocol (Fig. 1a, lane 2) and both are separately isolated by the second protocol (Fig. 1b, lanes 2 and 4). According to zymogram analysis of samples from the second protocol endochitinase activity is detected for the $61.2-\mathrm{kDa}$ enzyme and exochitinase activity for the $62.7-\mathrm{kDa}$ one (Fig. 1c, lanes 1 and 3). Further optimization of purification of the endochitinase resulting from the first protocol is currently under way.

The second purification protocol resulted in four samples, each with predominant presence of one component (Fig. 1b, lanes 2-5) of a single molecular mass as follows from SDS/PAGE confirmed by MALDI analysis. The resulting samples contain enzymes with molecular masses $61.2 \mathrm{kDa}$ (sample I), $85.3 \mathrm{kDa}$ (II), $62.7 \mathrm{kDa}$ (III), and $47.5 \mathrm{kDa}$ (IV), as it is represented by lanes $2,3,4$, and 5 in Fig. 1b, respectively. Enzymes present in samples I and III are the endochitinase and exochitinase already discussed for the first protocol. Their identity is currently (a) First purification protocol - SDS/PAGE, silver staining. Lanes 1: mass marker, 2: predominant presence of an endochitinase with mass $\sim 60 \mathrm{kDa}, 3$ : zymogram - detection of chitinase activity, (b) Second purification protocol - SDS PAGE, Coomasie Brilliant Blue staining. Lanes 1: mass marker, 2: sample I, mass $\sim 60 \mathrm{kDa}$, 3: sample II, mass $85 \mathrm{kDa}$, 4: sample III, mass $\sim 60 \mathrm{kDa}$, 5: sample IV, mass $45 \mathrm{kDa}$, 6: original culture fluid, (c) Zymograms. Lanes 1: endochitinase activity of sample I, 2: endochitinase activity of original culture fluid, 3: exochitinase activity of sample II, 4: exochitinase activity of original culture fluid. 
unknown and genes in closely related bacterial species for enzymes of corresponding molecular masses were not found. No $N$-acetyl- $\beta$-glucosaminidase activity was detected in samples I-IV.

Sample II contains predominantly chitinase B of glycosyl hydrolase family 18, an endochitinase whose homologues from other species have been intensively studied (van Aalten et al., 2001). Chitinase B was previously identified by peptide fragment mass spectroscopy analysis and most of its amino-acid sequence was determined. It is a homologue of chitinase B from Clostridium paraputrificum strain M-21 described by Morimoto et al. (2001; 2007).

Sample IV contains an enzyme with a molecular mass closest to the mature form of $N$-acetyl- $\beta$-glucosaminidase from Clostridium paraputrificum M-21 (Nag3A, UniProtKB Q84IZ5, calculated molecular mass 43244 without the signal sequence; Li et al., 2002). Further characterization of this enzyme is under way.

Other purification methods were also investigated. Precipitation of the concentrated supernatant followed by size exclusion chromatography of the remaining soluble fraction resulted in isolation of the $62.7-\mathrm{kDa}$ protein. However, its chitinolytic activity was probably lost during the process.

For the second protocol desalting was tested as the first step to remove the time-consuming size exclusion chromatography experiment. This approach was proved successful for separation of the $60-\mathrm{kDa}$ enzymes. However, it was not suitable for efficient separation of chitinase $\mathrm{B}$, the majority of which was lost during desalting.

Protocol 1 leads to isolation of the $61.2-\mathrm{kDa}$ endochitinase. Protocol 2 yields four enzymes of the chitinolytic complex and enables zymographic identification of distinct activities of the $60-\mathrm{kDa}$ enzymes. Size exclusion chromatography followed by anion exchange is currently the best method for obtaining sufficient amounts of chitinase $\mathrm{B}(85.3 \mathrm{kDa})$ and is also suitable for purification of the $60-\mathrm{kDa}$ chitinases. The purification protocols are reproducible and the individual enzymes will be characterized further. Chitinase B identified in the extracellular extracts of Clostridium paraputrificum J4 and partly purified is the best candidate for structural studies.

Several critical parameters have been found for the identification and characterization of a whole spectrum of enzymes produced by this anaerobic bacterium. Saccharide-based materials must be avoided as most of the studied enzymes bind to such surfaces which results in significant losses. The initial purification step cannot be generalized for all the enzymes of the chitinolytic com- plex. Even if high throughput steps would have been ideal when processing the native extracts, such as desalting or ultrafiltration, to remove the high levels of organic and inorganic compounds, these were proved inefficient for isolation of sufficient amounts of higher molecular mass chitinases. Standard protein purification protocols used for structural studies are commonly completed by size exclusion chromatography. In this case we have discovered that this laborious procedure is the most suitable initial step in separation of the chitinolytic enzymes of higher molecular mass.

\section{Acknowledgements}

This project was supported by the Czech Science Foundation, project no. 310/09/1407 and 305/07/1073.

\section{REFERENCES}

Chang WT, Chen ML, Wand SL (2010) An antifungal chitinase produced by Bacillus cereus with shrimp and crab shell powder as a carbon source. J Microbiol Biotech 26: 945-950.

Dahiya N, Tewari R, Hoondal GH (2006) Biotechnological aspects of chitinolytic enzymes: a review. Appl Microbiol Biotechnol 71: 773-782.

Flint HJ, Zhang JX, Martin J (1994) Multiplicity and expression of xylanases in the rumen cellulolytic bacterium Ruminococcus flavefaciens. Curr Microbiol 29: 139-143.

Fukamizo T (2000) Chitinolytic enzymes: catalysis, substrate binding, and their application. Curr Protein Pept Sci 1: 105-124.

Khan A, Williams K, Molloy MP, Nevalainen H (2003) Purification and characterization of a serine protease and chitinases from Paecilomyces lilacinus and detection of chitinase activity on $2 \mathrm{D}$ gels. Protein Expr Purif 32: 210-220.

Li H, Morimoto K, Katagiri N, Kimura T, Sakka K, Lun S, Ohmiya K (2002) A novel $\beta$ - $N$-acetylglucosaminidase of Clostridium paraputrifcum M-21 with high activity on chitobiose. Appl Microbiol Biotechnol 60: $420-427$.

Morimoto K, Karita S, Kimura T, Sakka K, Ohmiya K (2001) Characterization of Clostridium paraputrificum chitinase A from a recombinant Escherichia coli. J Biosci Bioeng 92: 466-468.

Morimoto K, Yoshimoto M, Karita S, Kimura T, Ohmiya K, Sakka K (2007) Characterization of the third chitinase Chi18C of Clostridium paraputrificum M-21. Appl Microbiol Biotechnol 73: 1106-1113.

Šimůnek J, Kopečný J, Hodrová B, Bartoňová H (2002) Identification and characterization of Clostridium paraputrificum, a chitinolytic bacterium of human digestive tract. Folia Microbiol 47: 559-564.

Tishchenko G, Koppová I, Šimůnek J, Dohnálek J (2010) Extracellular complex of chitinolytic enzymes of Clostridium paraputrificum strain J4 separated by membrane ultrafiltration. Folia Microbiol 55: 386-389.

van Aalten DMF, Komander D, Synstad B, Gåseidnes S, Peter MG, Eijsink VGH (2001) Structural insights into the catalytic mechanism of a family 18 exo-chitinase. Proc Natl Acad Sci USA 98: 8979-8984.

Vernazza CL, Gibson GR, Rastall RA (2005) In vitro fermentation of chitosan derivatives by mixed cultures of human faecal bacteria. Carbohydr Polym 60: 539-545.

Vicencio AG, Narain S, Du ZF, Zeng WY, Ritch J, Casadevall A, Goldman DL (2008) Pulmonary cryptococcosis induces chitinase in the rat. Respir Res 9: 40. 